\title{
Opting for assets to enrich pre-school learning
}

\author{
I. Eloff ; A. de Wet \\ University of Pretoria, South Africa
}

\begin{abstract}
This research entailed an ethnographic study that sought assets and resources to enrich pre-school learning in a community challenged by poverty. The aim of this research was to identify personal and environmental assets that could be used to enrich pre-school learning within this context - instead of focusing on needs and deficiencies. The assets included objects and artefacts that could be used for pre-school learning. Observations, field notes, interviews, photographs and artefacts were used to study the community while participating as a member of the community. Numerous assets were identified. Seven main themes were derived from a collective summary of data. The main themes were: children, culture, man-made products, the natural environment, local institutions and citizens' associations, crafts and caretakers. The themes were expanded into categories and subcategories. The results of this research study suggest that this particular community is rich with potential, opportunities and material to enrich the pre-school learning of children.
\end{abstract}

Keywords: Asset-based approach; Culture of poverty; Environmental assets; Ethnographic study; Personal assets; Pre-school learning

\section{Introduction}

This article reports on an ethnographic study that sought to find pathways for enriching pre-school learning by opting to focus on assets and available resources. It was conducted in a community challenged by poverty. The aim was to identify personal and environmental assets that could be used to enrich the pre-school learning of the community's children. These assets included anything that could be used for pre-school learning, including man-made objects such as tyres and items found in the natural environment. Observations, field notes, interviews, photographs and artefacts were used to collect data. Numerous assets were identified.

Early childhood intervention attempts to help young children to become more accomplished adults (Stacks, 2005). Early experiences influence the growth and development of neural pathways in the individual (Shonkoff \& Meisels, 2000). In the growing child there is a profusion of synapses connecting the brain cells present. This means that during the years from age 3 to 10, the brain is more densely connected than at 


\section{openUP}

any other time in the child's life (Shonkoff \& Meisels, 2000). Therefore, the early years are a very sensitive time for that portion of the brain that controls complex functions such as language acquisition and logical thinking. As connections in the young child's brain are reinforced when they receive stimulation, and are eliminated without stimulation, the quality of the young child's environment has a critical influence on his or her capacity to develop an adequate foundation for later learning and emotional regulation (Shonkoff \& Meisels, 2000). Learning never takes place in isolation, but arises from interactions with others (Williams \& Burden, 1997). Early intervention acknowledges the aspects of biology and culture and their dynamic influences on each other (Emde \& Robinson, 2000). Early intervention can be carried out in a formal or informal way (Kriek \& Eloff, 2004).

In South Africa there are many children under the age of six years that grow up in poverty. Streak (2002) indicates that about $60 \%$ of South Africa's children (age 0-17), or 10.5 million children, have too little income to live a healthy and secure life. About 3.8 million of these children are younger than age six. They can be defined as being at-risk regarding optimal early development. The effective support of children under the age of seven years is furthermore harmed by unemployment, illiteracy, urbanisation and HIV \& AIDS (Kriek \& Eloff, 2004). Rossetti-Ferreira and Ramon (2000) state that not doing early childhood intervention in a country such as South Africa leads to social risk factors such as:

...Higher child morbidity rate, later school enrolment, higher repetition rate, more school drop-outs, poor school performance, lower future income and taxes, mother work force that are tied up at home, older sisters taken out of school to take care of younger siblings and higher crime rates.

Early childhood intervention can be considered a powerful future investment (Eloff \& Ebersöhn, 2001). In South Africa the social context often necessitates an asset-based approach to early intervention that stresses capacity building and internal control.

One of the challenges facing children and families is poverty and its underlying causes. An increasing number of children are growing up in poverty and have no access to sufficient pre-school education. The children are faced with the stresses of hard-working, low-income families (Shonkoff \& Meisels, 2000). The families also find that a large portion of their income goes into basic childcare, which is often of a lesser quality than can be obtained by families with greater income (Shonkoff \& Meisels, 2000).

Disadvantage in particular social and educational contexts often results in a set of barriers to learning (Donald et al., 1997). One of the main arguments for using assets is that without some emphasis on assets, children may not have the maximum opportunity to realise their potential and escape poverty (Sherraden, 2003).

The needs-based approach, even though well intended, often results in a long list of deficiencies and what is lacking in communities. References to potential assets are mostly elliptical. This can have a potentially debilitating effect on both the community and the researchers involved. The needs-based approach is regarded as inefficient in addressing 


\section{openUP}

the challenges of society in the South African context (Eloff \& Ebersöhn, 2001) because the approach is seldom associated with real change or development. This approach may create a perception that only external experts will be able to solve the perceived problems, and this in turn contributes to a sense of hopelessness, because solutions are situated extrinsically.

However, we have choices in terms of our approach in community development in general, and early childhood intervention specifically. The asset-based approach does not imply that the deficiencies in a community can be negated, but, by focusing on strengthening the assets of a community, the deficiencies can be addressed (Eloff \& Ebersöhn, 2001). The asset-based approach is a bottom-up approach that shifts the emphasis from a services perspective to an empowerment perspective. The asset-based approach proposed in this research offers some possibilities in overcoming the disempowering effects of the needs-based approach. It has been described as an approach that regards 'the glass as being half full, rather than half empty' (Kretzmann \& McKnight, 1993). It focuses on potential assets and capacities in the community that can be mobilised to ensure sustainability.

In this research the community as a whole was studied in a search for personal and environmental assets that can be used to enrich pre-school learning. Assets were looked for in the community because they were already part of the community as they had potential as sustainable resources. The rationale for adopting this approach in this research is the fact that it has been used with great success in other contexts, and we believed that an ethnographic study on enriching learning during the early years in the South African context can provide rich indigenous knowledge.

\section{Research question}

The research question of this study comprised asking:

- What assets within children, caretakers and the community can be used to enrich the education and learning of pre-school learners within a culture of poverty?

\section{Background to the study}

A Swazi settlement has been purposefully selected for this research. In southeastern Africa, Swazi-speaking people live chiefly in Swaziland and South Africa. More Swazispeaking people live in South Africa, however, than in Swaziland itself. The Swazi people migrated from central Africa in the fifteenth and sixteenth centuries with the Xhosas and Zulus, which belong to the Nguni subgroup (Swaziland Government, 2006). After breaking away from the mainstream Nguni migrants, they settled in the region of the Pongola River. There are limited supplies of portable water, and wildlife is under threat because of excessive hunting and overgrazing.

Mangweni is a town near the border of Swaziland. The town is in South Africa, approximately where South Africa, Mozambique and Swaziland meet. The town houses a 


\section{openUP}

few thousand people. Geographically the town is divided in two by a single tar road that runs through the middle of the town. The rest of the town has only roads that are not tarred. A few traditional Zulu huts can still be seen, but most of the people live in houses built from sandstone. The dominant mother tongue in the community is Swazi, and some community members speak Zulu. Many of the teenagers and young people, who go to high school, can speak some English.

There are many churches in Mangweni. There are a few primary schools and two high schools. There is also a clinic in the town - it delivers services to pregnant woman, infants and young children.

Mangweni is situated in a tropical area. Many fruit trees can be found all year long. It is a very hot area with a prevalence of malaria in summer. Most of the houses have electricity. Approximately every second house has a tap in the yard with running water during specific hours in the day - usually early in the morning. Due to the scarceness of water, very little grass can be seen. People usually keep chickens on their yards for eggs and meat. Cattle and goats are also kept.

Families mostly consist of a mother and many children, ranging from teenagers to babies. Fathers are often absent due to work opportunities far away or separation between the parents. Many teenage girls have their own babies that are financially supported by the grandmother. There are a lot of children in Mangweni and many mothers work in Malelane. Often mothers are away at work all day and only come home after dark. However, many mothers are without work and spend the day looking for work or food.

Sampling was an ongoing process throughout the research. To the ethnographer, a single site is important. A site was chosen where children and caretakers could be located. Because the focus of this study is mainly on pre-school children and caretakers, the presence of children was a criterion for the selection of interviewees. Opportunistic sampling was used when advantage was taken of opportunities; for example when a mother or other caretaker with siblings was noticed, they were approached for an interview.

\section{Methodology}

\section{Ethnography}

In this study ethnographic research was used to identify assets to enrich pre-school learning within a culture of poverty. In comparison with other social scientific qualitative approaches, ethnography generates a rich methodological literature (McLeod, 2001). Ethnography can be defined as the study and art of describing the way of life of a culture. Ethnographers are interested in all aspects of human behaviour: roles, rituals, language, religion, food, history and physical environment (McLeod, 2001). The primary method of ethnographic research is participant observation in fieldwork. This procedure consists of spending time with people, taking part in their daily routines, listening to them and asking questions. Ethnographic research is capable of capturing quality and characteristics 


\section{openUP}

within a social context (McLeod, 2001). The key research strategy in ethnography is the willingness of the researcher to spend long periods of time in the field. The openness of the researcher to learn from this period of cultural immersion is the main criterion for success (McLeod, 2001).

During this research one of the researchers was involved as a guest of the community. She lived with people in their houses and interacted as part of families. Through interaction with members of the community she conducted the research, since the principal method of ethnographic research is, after all, participant observation (Cohen et al., 2001).

For ethnographic research, the researcher has to spend extended periods of time in the field. The researcher spent seven periods of one week each over a period of three years in the community. During this time she conducted interviews and observations, took photographs and field notes and also collected artefacts. Throughout, an asset-based approach was used as the theoretical framework for the study. Resources and structures within the existing community were studied to identify elements that can be used to enrich pre-school education and to stimulate learning. This research was mainly utilising inductive logical reasoning.

\section{Data collection}

Data were collected through observations, field notes, interviews, photographs and artefacts. These collecting methods were aimed at drawing rich material from the research site:

- Through observation, the natural surroundings were studied to identify assets that can be used for pre-school education and learning.

- Ethnographic observations and interviews were used to identify the caretakers.

- Ethnographic observations and interviews were used to learn about the activities of the caretakers and their responsibilities.

- Observations and interviews were used to learn about the caretakers' interaction with the children.

- Interviews were used to estimate the potential of the clinic as resource for preschool learning.

- Interviews and observations were used to identify any kind of pre-school stimuli that already existed.

- Observations were used to identify toys that children play with.

- Observations and interviews were used to identify the activities of children during the day.

Observations were carried out over a three-year period for seven periods of one week each. Mostly children and their caretakers were observed. The environment, surroundings, institutions and the culture were noted. Field notes were only written during the last week of the research to minimise the distancing effect that overt notetaking might have. Notes were then written on all observations done during the last week 


\section{openUP}

of research. Notes were also written as reflections on assets that were identified. Field notes were written in a notebook that was analysed after returning from the field.

Twenty-five interviews were conducted with caretakers. With the consent of participants, interviews were taped with an audiocassette player. After returning from the field, further notes were also written about the interviews. With the consent of participants, 67 coloured photographs were taken during the last week of research. Photographs were taken of children playing and doing chores as well as of surroundings. Photographs were also taken of the clinic. Artefacts were collected during the last week of research. They mostly consisted of crafts made by caretakers and children.

\section{Data analysis}

To analyse the data, each one of the data-sets (observations, interviews, photographs and artefacts) was analysed on its own. After assets were identified in each set of data, the four sets of assets were compared to eliminate duplication of assets. A collective summary of assets was derived from these. The assets were studied and themes were formed. Assets were compared and contrasted until all assets were grouped as themes. Seven themes emerged. Themes were expanded into categories and categories into subcategories.

These assets can be used to enrich pre-school learning in a culture of poverty. The assets can be used in activities or practicing skills needed for learning. Furthermore, the learning outcomes for the foundation phase in South Africa, as stated by the Revised National Curriculum Statement (2002), are met by using these assets. The final phase of data analysis involved linking the identified assets for pre-school learning with activities for which it can be used, the pre-school learning skills that can be practiced and the potential learning outcomes.

\section{Findings}

The findings of this research study are summarised in Table 1. Assets are grouped under three headings: asset themes, categories and subcategories. As the assets were compared seven themes were found that enabled the researchers to categorise the assets in such a way that the community members could clearly see in which categories each of their assets fell; this enables them to structure the activities they use for pre-school learning skills. 


\section{Table 1. Summary of research results}

Asset theme

Children

Culture

Man-made products

Natural

environment

\section{Category}

Games

Bodies

Peers

Evenings

Toys

Chores

Leisure time

Characteristics

Activities

Dances

Importance of

children

Presence of

children

Songs

Household items

Egg boxes, candle wax, coals, wooden benches, cutlery, sheets, blankets, table cloths, washing lines, buckets, plastic containers, cooking utensils, furniture, radio, television, chairs, cold drink cans, curlers, maize meal bags, plastic bags, fabrics, rope, tins, pens, papers, books, drums

Clothes Washing clothes, baby napkins

Buildings

Garden tools

Old broken vehicles and machinery

Roads

Animals

Insects

Plants
Rope jumping, ball games, language games, running games, singing games, dancing games, hide and seek, competitions, netball, football

Bodies, fingers, hair-plaiting

Sit and talk, learn prayers

Modern toys, electronic toys, swings, hula-hoops, balloons filled with sand, cards, toy guns

Work in garden, washing dishes

Very independent, like to interact, not scared of people or strangers

Jumping, reading, writing, crawling, counting 


\section{Table 1. Summary of research results}

Asset theme

Category

\section{Subcategory}

orange and lemon seeds, mango seed, avocado seed, sugar cane, wood, trees, climbing trees, peanuts, beans, pods, grains of maize, mealie stalk, sweet potatoes, sticks, long grass, thorns, leaves, cotton

Soil

Sand

Stones

Mud figures

Drawing in the sand, sand in a bottle

In the garden

Big yards

Water

Garden

Local

institutions and

citizens'

associations

Churches

Special schools

Clinic and nurses Waiting time at clinic, waiting area at clinic

Market

Schools School books

Small businesses Tuck-shops at houses, fruit stalls next to roads

Crafts

Toys Wire cars, dolls.

Household items Grass brooms, grass mats, mats made from plastic bags

Clothes Hats crocheted from plastic bags, traditional skirts

Decorations Plastic straw decorations, straw decorations, carton stars covered with fabric, beads

Vegetable gardens at houses

Sunday school, church meetings

Caretakers Chores

Mothers

Grandmothers

Family

Siblings

Neighbours

Big yards

Teachers

Leisure time 


\section{openUP}

\section{Discussion of research results}

In this research study, numerous assets to enrich pre-school learning were identified, and mobilising it could have a constructive outcome. As researchers we believe that each learning environment boasts a unique combination of assets and capacities; and if these assets are recognised, it can contribute to the creation of an effective learning environment.

Each asset was related to activities the asset can be used for to enrich pre-school learning, the skills practiced by these activities and the learning outcomes for the Foundation Phase in South Africa, as stated by the Revised National Curriculum, practiced. Using these assets as resources for pre-school learning, all the learning outcomes for the Foundation Phase were covered. Therefore, one can conclude that there is an ample amount of resources present in the community to enrich pre-school learning. Assets are everyday objects and activities present in most households, as can be seen in the assets identified in this study. These everyday objects and activities have a lot of potential for enriching preschool learning. These assets give practical solutions for problems; for example, children can practice their fine motor skills by writing in the sand with a thorn or practicing handeye coordination by playing ball games with a lemon. These assets can effectively be used in intervention programmes. Intervention programmes should be aimed at maximising opportunity factors (Wolery, 2000). Intervention programmes should be based within the local community as caring relationships and human connections are essential to healthy growth and development (Krueger, 1998). It is important to note that supported youth know they are not alone; they know they can rely on positive, fulfilling relationships with numerous adults in their families, schools and communities (Scales \& Leffert, 2004). Because these assets were identified within the community, they are replaceable when broken; for example, a broken wooden bench can easily be fixed or replaced. The assets identified in this study are also inexpensive and can be used innovatively to enhance pre-school learning.

Intervention with a competency-based approach looks at the child holistically (Wilson, 1998). The results of this research study can be used as a different point of departure when looking at intervention. Intervention can consist of starting with the assets of the child. This research study identified children as an asset. This includes the games the children play, such as rope jumping, ball games, language games, running games, singing games, dancing games, hide and seek, competitions and mimic games. These games cover a variety of skills and learning outcomes that are practiced by playing these games. It can facilitate the general development of children as well as peer interaction (Alant, 2003). The child's own body was identified as an asset to teach children vocabulary, visual motor skills, auditory perception, memory, musicality, numeracy, self-worth, independence, language, emotional development, measuring, social skills and fine motor skills. Peers were identified as an asset for developing social skills and independence. 


\section{openUP}

The toys (modern toys, electronic toys, swings, hula hoops, balloons filled with sand, play cards and play guns) of the children are assets that can be used in a variety of ways to enrich pre-school learning. The way in which evenings are spent, talking and teaching prayers to the children, is an asset to this community. Chores with which the children have to help, such as working in the garden or washing dishes, can enrich the learning of pre-school learners. The ample leisure time available to children can be used for any activity enriching pre-school learning. Characteristics of the children (their independence, their preference for interaction and their boldness towards people) put them in a favourable situation for learning and development. Activities of children (jumping, reading, writing, crawling and counting) have been identified as assets with a variety of applications to enrich pre-school learning.

The culture of this community has been identified as an asset to enrich pre-school learning. Songs are part of community members' lifestyle. Children are exposed to songs from a very young age. This enhances the children's musicality, rhythm, vocabulary and auditory perception. Dances, too, are common in the community. Dancing contributes to the children's rhythm, musicality, gross motor skills, coordination, imagination and social skills. Making music is another asset contributing to children's musicality, rhythm and creativity. Furthermore, the importance and the presence of children in the company of adults are identified as assets that enrich identity and self-worth.

Young children learn through play and through interactions with people and objects in their environment (Wilson, 1998). Man-made products were identified as assets to enrich pre-school learning. Everyday household items such as egg boxes, candle wax, coals, wooden benches, cutlery, sheets, buckets, plastic containers, cooking utensils, furniture, radio, television, maize meal bags, plastic bags, fabrics, rope, tins, pens, papers, books and drums can be used in different ways to develop skills related to pre-school learning. The clothes that the children wear are an asset. The activity of washing clothes can teach children aspects of numeracy, new vocabulary and visual perception. Folding baby napkins into shapes can also contribute to the child's visual perception. Buildings in a child's environment are assets. Bricks, fences and steps at houses can be used for the development of balance, imagination, numeracy, fine motor skills, gross motor skills, measuring and coordination. Garden tools like hosepipes and wheelbarrows can be applied to create activities to enrich pre-school learning. Old tires are an asset for the practicing of gross motor skills, balance and creativity. The roads in the community are an asset for playing games and socialising with friends.

Wilson (1998) recommends that children be provided with optimal environments to increase their intellectual development. The process of learning is based on experiences gained in interaction with the environment that provides messages to the learner. Accessibility to the environment fosters independence, feelings of competence and active exploration to the child (Wilson, 1998). Queiros (2001) describe three types of environmental education: education about, through and for the environment. Education about the environment aims at discovering the nature of the environment, education through the environment uses the environment as a medium for learning, and education for the environment develops an informed concern for the environment. Environmental 


\section{openUP}

education stresses the importance of integrating conceptual knowledge with sensory and perceptual development. In this research study, many assets to enrich pre-school learning were identified within the natural environment. Assets included animals (chicken feathers, chickens, dogs, cattle, donkeys and goats) and insects that can be used to teach children about these creatures and how to care for them. Plants or parts of plants such as husks of maize, oranges, lemons, papaya and pumpkin seeds, orange and lemon seeds, mango pit, avocado seed, sugar cane, wood, trees, peanuts, beans pods, grains of maize, mealie-stalk, sweet potatoes, sticks, long grasses, thorns, leaves and cotton were identified as assets with various ways in which they can be used to enrich pre-school learning. Soil used for mud figures is an asset for the development of fine motor skills, creativity, numeracy and tactile perception. Sand was identified as an asset for drawing (in the sand) and pouring sand into a bottle. Stones are an asset to promote numeracy, creativity and auditory perception. The big yards in the community are an asset for gross motor skills and social skills. Water can be used in many ways to enrich pre-school learning and was identified as an asset. Vegetable gardens are an asset when they are used to teach children colours, sizes, seasons and entrepreneurship.

Local institutions and citizens associations were identified as assets to enrich pre-school learning. Local churches hold church meetings and Sunday school, during which children are actively involved and have the opportunity to develop in terms of morality, auditory perception, musicality, memory, self-assurance and social skills. Church buildings that are vacant during the week can be used as a playgroup, a crèche or a venue for parent guidance. Crèches in the community offer a variety of opportunities to children for preschool development. Schools in the community hand out schoolbooks to enrolled students who can take books home. At home, younger siblings can benefit from these books when a parent or older siblings read to them. Special schools in the community accommodate learners with special needs but can also give learners in mainstream education the opportunity to learn how to socialise with people with special needs. The local clinic was identified as an asset because of the waiting time at the clinic and the waiting area. The waiting area lends itself to display toys to enrich pre-school learning to visiting mothers. The long waiting hours can be used to show mothers, who are waiting to have their babies examined, examples of toys (like a can filled with stones), illustrating how to use it to stimulate learning. The clinic can be used as a venue for an intervention programme to provide caretakers with training and support in influencing their children's interactions with the environment. Caretakers can be empowered to understand the importance of the first six years for later life and their role as caretaker. They can also acquire skills to use resources to facilitate pre-school learning. When caretakers take children to the market, children get exposed to the business world. The marketplace can also facilitate learning of other concepts such as size, shape and colour. Small businesses in the community give children the opportunity to buy by themselves and help parents sell products. This facilitates the learning of entrepreneurship and numeracy.

Caretakers can expose children to music, art or other creative activities. As they mature, children can participate in these activities regularly. These fun and meaningful activities can help children become caring, confident and creative adults (Roehlkepartain \& Leffert, 2000). Crafts were identified as an asset in the community. Children can make 


\section{openUP}

different kinds of decorations such as plastic straw decorations, straw decorations, cardboard stars covered with fabric and decorations with beads. This will help the children to develop fine motor skills, creativity and concentration. They can also make their own toys, like wire cars and dolls, learning fine motor skills, imagination, creativity, responsibility and gender. Making household items such as grass brooms, grass mats and plastic bag mats not only teaches children fine motor skills, but can also be used to play and learn with. Clothes such as hats crocheted from plastic bags and traditional skirts are assets for the development of fine motor skills and to play with; for example, during fantasy play.

To grow and thrive, children need supportive adults. Anyone who spends time with children can love, care for, encourage and affirm them (Roehlkepartain \& Leffert, 2000). The caretakers in this community include mothers, grandmothers, family, siblings, neighbours, friends and teachers. Caretakers and children spend a lot of time together in predictable and enjoyable routines. Caretakers that provide appropriate supervision of children are an asset in this community.

\section{Conclusion}

The aim of this research was to identify personal and environmental assets that could be used to enrich pre-school learning within a culture of poverty. These assets included anything that could be used for pre-school learning. Numerous assets were identified. The results of this research study suggest that this particular community is rich with potential, opportunities and material to enrich the pre-school learning of children.

\section{References}

Alant, E. (2003) Early childhood intervention: let's take on the challenge.

Perspectives in Education 21:(1), pp. 209-210.

Cohen, L., Manion, L. and Morrison, K. (2001) Research methods in education (5th edn), Taylor \& Francis , London

Donald, D., Lazarus, S. and Lolwana, P. (1997) Educational psychology in social context: challenges of development, social issues, special need in Southern Africa - a teacher's resource Oxford University Press , Cape Town

Eloff, I. and Ebersöhn, L. (2001) The implications of an asset-based approach to early intervention. Perspectives in Education 19:(3), pp. 147-157.

Emde, R. N. and Robinson, J. (Shonkoff, J. P. and Meisels, S. J. eds.) (2000) Guiding principles for a theory of early intervention: a developmental-psychoanalytic perspective. Handbook of early childhood intervention The Press Syndicate of the University of Cambridge, Cambridge 


\section{openUP}

Kretzmann, J. P. and McKnight, J. L. (1993) Building communities from the inside out ACTA Publications , Chicago, IL

Kriek, T. and Eloff, I. (2004) Verkenning van 'n bategebaseerde benadering tot vroeë intervensie. South African Journal of Education 24:(2), pp. 133-140.

Krueger, M. A. (1998) Interactive youth work practice CWLA Press , Washington, DC

McLeod, J. (2001) Qualitative research in counseling and psychotherapy SAGE Publications, London

Queiros, D. (2001) Environmental education in the urban environment: an innovative approach. South African Journal of Education 21:(2) , pp. 67-71.

Revised National Curriculum Statement (2002) (Pretoria, Department of Education)

Roehlkepartain, J. L. and Leffert, N. (2000) What young children need to succeed working together to build assets from birth to age 11 Free Spirit Publishing, Minneapolis, $\mathrm{MN}$

Rossetti-Ferreira, M. C. and Ramon, F. (2000) State of the art lecture: improving early child care and education in developing countries. paper presented at the International Congress of Psychology Stockholm, Sweden

Scales, P. C. and Leffert, N. (2004) Developmental assets: a synthesis of the scientific research on adolescent development (2nd edn), Search Institute, Minneapolis, MN

Sherraden, M. (Paxton, W. ed.) (2003) Assets and the social investment state. Equal shares? Building a progressive and coherent asset-based welfare policy pp. 28-41. Institute for Public Policy Research, London

Shonkoff, J. P. and Meisels, S. J. eds. (2000) Early childhood intervention Cambridge University Press , Cambridge

Stacks, A. M. (2005) Using an ecological framework for understanding and treating externalizing behavior in early childhood. Early Childhood Education Journal 32:(4) , pp. 269-278.

Streak, J. (2002) New results on child poverty in South Africa. Available online at: www.idasa.org.za/bis/briefs/default.htm (accessed 20 November 2006)

Swaziland Government (2006) Online information portal. Available online at: www.gov.sz (accessed 22 November 2006) 


\section{openUP}

Williams, M. and Burden, B. R. L. (1997) Psychology for language teachers: a social constructivist approach The Press Syndicate of the University of Cambridge , Cambridge

Wilson, R. A. (1998) Special educational needs in the early years Routledge, London

Wolery, M. (Shonkoff, J. P. and Meisels, S. J. eds.) (2000) Behavioural and educational approaches. Early childhood intervention Cambridge University Press, Cambridge 